European journal of American studies

Special Issue: Contagion and Conviction: Rumor and Gossip in American Culture

\title{
From the Whisper Network to \#MeToo-Framing Gender, Gossip and Sexual Harassment
}

\section{Maria Verena Peters}

\section{(2) OpenEdition \\ Journals}

Electronic version

URL: https://journals.openedition.org/ejas/16587

DOI: $10.4000 /$ ejas. 16587

ISSN: 1991-9336

Publisher

European Association for American Studies

Electronic reference

Maria Verena Peters, "From the Whisper Network to \#MeToo-Framing Gender, Gossip and Sexual Harassment", European journal of American studies [Online], 15-4 | 2020, Online since 17 December 2020, connection on 08 July 2021. URL: http://journals.openedition.org/ejas/16587 ; DOI: https:// doi.org/10.4000/ejas. 16587

This text was automatically generated on 8 July 2021.

Creative Commons License 


\title{
From the Whisper Network to \#MeToo-Framing Gender, Gossip and Sexual Harassment
}

\author{
Maria Verena Peters
}

\section{Introduction: Gender and Gossip}

1 The ideological linkage between gender and gossip is deeply ingrained in Western, patriarchal culture. The notion that "women gossip more than men" (Leaper and Holliday 237) fulfills a crucial function within patriarchy. In his seminal 1977 paper "How the 'Gossip' Became a Woman," Alexander Rysman elucidates this ideological function and the history of the nexus between femininity and gossip. The term "gossip," Rysman explains, shifted from initially denoting a person close to the family (a "god sib") to the kind of talk done by people of such close relations. "Gossip" started out as a gender-neutral term and only gained a negative connotation when it began to denote specifically feminine behavior in the $19^{\text {th }}$ century (176). In other words, while men may have warm, friendly talks with each other over a drink, women engage in mean and treacherous idle talk: they gossip. Linguistic studies, Rysman warns, need to be aware of this bias so as not to repeat it. Rysman's hypothesis for the dynamics of the negative connotation of female gossip is a fitting description of women's experience in patriarchal societies which holds true more than 40 years later:

\footnotetext{
Women together can make trouble for men.... Any relation between women... is subject to the charge of being a gossip and hence any woman who relates to other women is subject to stigmatization as a 'gossip.' Thus for the 'gossip' to develop social ties outside of the institutions of male dominance becomes the major sin. (180)
}

2 The label "gossip," when applied to a woman or women's talk, is understood as a discursive weapon of the patriarchy to disparage bonds women may form.

3 In the twenty-first century, the term "gossip" still fulfills the same function. In 2017, Time Magazine chose not one, but five persons for their "person of the year" cover: five 
women, dubbed as "silence breakers" by the magazine. Among them was Susan Fowler, an engineer who wrote a blog about her experience of sexual harassment and gender discrimination at the successful start-up Uber in February 2017, titled "Reflection on one very, very strange year at Uber." Fowler's blog quickly went viral. Maybe even more unsettling than Fowler's experiences of sexual harassment at Uber was, according to her account, the utter failure of the company's own structures to deal with these issues properly. Following one of her last complaints, Human Resources accused her of being an instigator and asked her "if women engineers at Uber were friends and talked a lot" (Fowler n. pag.), the implication being that there was a gossip circle of female engineers with her acting as leader. The incident displays the very dynamic described by Rysman fourty years ago: women who cause trouble are punished with the stigma of being a gossip and thus others are discouraged from associating with them or following their example. Fowler's statement to Time about her blog and the way she wrote it shows her awareness of that stigma:

When other women spoke out, they were retaliated against. So there were certain things that I thought I could avoid: ... I can't have any emotion in my blog. I have to be very, very detached. And I had to make sure that every single thing that I included in there had extensive physical documentation, so it couldn't be 'he said, she said'. (Time 43)

4 In other words, Fowler felt she had to presuppose that her credibility would be scrutinized and therefore compose her blog in such a way that there could be no possibility to shrug it off as, precisely, gossip. This example not only demonstrates the stigma's potential for stifling solidarity among women and, more generally, their outspokenness, but also defines their discourse if they do speak out.

There is a double bind at the heart of how the term gossip has been used as a discursive weapon against women: they are depicted as a gossip and at the same time they are made into the object of gossip once they have spoken out. Singling them out as troublemakers, instigators, and gossips amounts to starting rumors and gossip about them in order to discredit them in the eyes of the public. The private lives of women who have accused powerful men of sexual harassment or rape have been exposed by the media and they have been depicted as "easy women" who were essentially "asking for it." In her 1977 essay "Rape, the All-American Crime," Susan Griffin used the case of The People Vs. Jerry Plotkin to exemplify how women become the objects of rumors and gossip in order to discredit them in the courtroom. The accused, Jerry Plotkin, was charged with abducting and raping a woman, but was eventually acquitted after the latter was successfully depicted as a sexual libertine and a bad mother by the defense. Up until recently, the same strategy could be observed in print media: In the 2018 editorial of the European Journal of Women's Studies, Dubravka Zarkov points out that "media have turned against the accusers, not the accused" (5) in the infamous cases of Anita Hill, who accused Supreme Court Justice Clarence Thomas of sexual harassment in 1991, and of Nafissatou Diallo, the hotel maid who was the first of many women to accuse Dominique Strauss-Khan, then the director of the International Monetary Fund, of sexual assault in 2011.

6 To sum up, gossip works against women in two ways: "gossip," as a label for women's talk, functions as a strategy to silence women. It denounces or prevents communication amongst women in public discourse. Assigning this label to their statements is a weapon used against women to discredit them both in the media and in the courtroom. 
Before \#MeToo, women who spoke up against harassment were thus simultaneously denounced as a gossip and-paradoxically - also made into the objects of gossip.

\section{A New Climate}

7 The year 2017 marked a turning point because of the way in which Susan Fowler's account, as well as those of other female "silence breakers" throughout the year, were received by the media-the Time's person of the year cover is only one piece of evidence of this new climate. However, the reaction that Fowler and others had feared-being denounced as a gossip not just by the accused, but also by the general public-has had countless precedents. Zarkov observes: "Today, we see the opposite: media seem to believe the accusers, fully and unconditionally-precisely what feminists hoped for since the 1970s! But should we rejoice about it? What are media doing here?" (8) Zarkov suspects that the visibility created by social media movements such as \#MeToo will not lead to legal actions and social change, but rather replaces both. There seems to be a general feeling, she argues, that the problem has been understood, dealt with, and solved, simply because it has been made visible as a hashtag. In the rare cases where actual consequences ensued for the accused, they were individual, not systemic, Zarkov concludes:

So I am worried that the fact that some of the famous Big Men-like Harvey Weinstein and Kevin Spacey-are basically finished, does not signal a social change. Rather it simply illustrates the mechanisms of self-preservation of a system that both makes these men the way they are, and then pukes them out when they become a liability. (8)

The positive media echo that \#MeToo has received, she argues, only simulates change to keep up the status quo with minimal sacrifices. This argumentation ultimately boils down to the question of the objectives of contemporary feminism and the place of hashtag feminism within the feminist movement. At the turn of the century, Angela McRobbie described a sentiment she witnessed among young women who felt that feminism is a thing of the past, that the feminist battle is over and that equality has already been achieved. She labels this phase "post-feminism" (255). Recently, however, feminists like Catherine Rottenberg have observed "a feminist renaissance of sorts" (Banet-Weiser et al. 16); social media, more specifically hashtag feminism, is an integral part of this phenomenon:

[W] have seen an explosion of feminist hashtag activism, from \#bringbackourgirls to \#solidarityisforwhitewomen to \#yesallwomen to \#NotOkay and, of course, to \#metoo. The blogosphere has become an important site for feminists to express passionate defences and celebrations of feminism and exhortations towards feminist and anti-racist activism (Banet-Weiser et al. 9)

This rekindling of feminism entails that young women recognize that equality has actually not yet been achieved-however, their approach to how these inequalities can be challenged differs fundamentally from those of previous generations of feminists. There appears to be a widely shared optimism that gender discrimination can be dealt with-quickly-by simply pointing it out on Facebook, Twitter or other social media platforms. This strand of feminism postulates visibility as a quick-fix solution to fundamental gender inequalities. Banet-Weiser labels this phenomenon "popular feminism" and elaborates: "[p]opular feminism thus relies in some ways on "platform capitalism"' (Banet-Weiser et al. 10f.). Based on the findings of Hearn and Gray, she 
argues that this entails the "the emptying or flattening out of the content of meaning, emphasizing instead the endless traffic and circulation of this content" and that "the visibility of popular feminism becomes an end in itself" (Banet-Weiser et al. 10f.). Banet-Weiser concludes that "most popular feminisms are typically those that become visible precisely because they do not challenge deep structures of inequities" (ibid., see also Banet-Weiser, 2018).

Banet-Weiser thus corroborates Zarkov's critique of hashtag feminism and is sceptical about the ability of such movements to bring about tangible social change. Research into the relatively new phenomenon of hashtag feminism that could support or refute this critique is scarce. In 2018, Mendes et al. published a case study of hashtag feminism in which they concluded:

$[\mathrm{H}]$ ashtags like \#BeenRapedNeverReported and \#MeToo provide important opportunities for the development of feminist solidarity and consciousness, and even, social change. This is especially true for girls and women who may not be familiar with feminism as a personal and political imperative. Indeed, these shifts in consciousness may go undetected at first, but over time, this 'mainstreaming' of feminist activism is laying the foundation for a collective shift towards a more just society. (239)

11 This "'mainstreaming' of feminist activism" achieved through hashtag feminism has had repercussions for the representation of rape survivors and feminist activists in the traditional media. However, before diving into the case studies, the specific features of social media as the cultural medium of hashtag feminism need to be outlined in order to point out their specificities. Social media offer a hybrid space that feels private and anonymous, yet which at the same time is very public. The public generated by social media is significantly different from that of traditional media, such as print or television: Firstly, social media enables interaction with a low inhibition threshold, and this interaction seems to have been necessary to win young women back for feminism. Secondly, women experience social media as a safe space for women-centered issues and communities in spite of the risk of online vitriol:

[D]espite the risk and hostility on Twitter, the digital sphere was still largely understood as a relatively safer and easier space to engage in feminist discussions than in participants' offline contexts. Moreover, we found that experiences of engaging with and developing feminist consciousness online actually created a range of clashes in their everyday relationships with colleagues, family and friends. The tension between their online feminist community where they could share views and opinions and get support contrasted strongly with experiences of dismissal by significant others in their everyday lives. (Mendes et al. 243)

The impression that social media is a safe space may, on the one hand, be rooted in the stigmatization of communication among women as gossip in offline social situations and, on the other hand, in the specific demographic of these platforms. As early as 2010, Johanna Blakley pointed out during at her talk at TEDWomen that the majority of social media platform users were females and that the amount of time women invested in these platforms daily was much larger than that invested by men (current statistics on "Social Media Use by Gender" 區Pew Research Center熙 show that this is still the case today). Blakley speculated that the fact that these platforms were female-dominated spaces (on the user, not the corporate level) was going to change-in the long run-how women were represented in all the other media. The entertainment industry, like all other industries, tailors its products on the basis of data they receive from market research. So, Barkley argues, when market research mainly delivers data 
generated from social media, a space predominantly frequented by women, companies will tailor their products according to women's preferences. She envisions that this might lead to changes as fundamental as an end to sexism in Hollywood movies-which so far still seems rather utopian. However, the new climate that rape survivors and feminist activists were encountering in traditional media was most likely an effect of movements on social media platforms. Thus, the third section of this paper provides an analysis of the way print media not only represented feminist activism happening on social media platforms, but also adapted their own strategies of representation to what was happening on social media platforms.

\section{Print Media in the Footsteps of New Media: Case Studies}

13 This analysis focuses on two case studies: one of them is \#MeToo and the activists in and around the movement. The representation of these key figures in print media will be analyzed with respect to the Time Magazine "Person of the Year" 2017 issue mentioned earlier. The second case study is the way New York magazine covered, during the summer of 2015, the women who accused entertainer Bill Cosby of rape. The latter feature was published earlier than the first, and can be regarded as an interesting precedent to the coverage of \#MeToo because it takes up a hybrid position by combining old and new media. The cover story titled "Cosby: The Women. An Unwelcome Sisterhood" received the Online Journalism Award in 2016. The award's jury described the features thus:

It began with the idea that the news reports of women coming forward could be transformed into something that might reframe the story and make it impossible to ignore. The result was an unconventional feature that, in its groundbreaking format in both print and digital, strove to convey the sheer volume of the accusations and to give each woman a clear voice of her own. ("2016 Feature, Large Newsroom, Winner. Cosby: The Women. The accounts of 35 Women who have Accused Bill Cosby of Sexual Assault.")

14 This hybrid piece of journalism consists of the testimony of the 35 women who accused Cosby of sexual assault, transcribed for the print version, including six filmed testimonies for the online edition, photographic portraits of each woman, a group collage for the magazine cover and Instagram "audiograms" combining portraits and voices to be placed on social media platforms. The text of the actual article consisted of an introductory essay by Noreen Malone and Amanda, as well as testimonies combined with the photographic portraits of the 35 women. The combination of a photo with a short personal testimony recalls the contribution format on facebook and Instagram. The testimonies allow the women to speak in their own voice-it is the kind of compilation of short personal statements typical of posts under activist hashtags on social media platforms, and the magazine seems to be strategically emulating this kind of representation. However, the particular visual appearance of the photographic portraits of the women stands in sharp contrast to the suggestion of individual agency evoked through their direct speech. All of them have been photographed in front of a white background, clad in virgin white clothes and photoshopped according to dominant beauty standards. A filter was used that gives the photos an appearance similar to oil paintings. The women have been turned into paragons of heavenly beauty with a perfectly composed, serene facial expression. It appears as if they were turned 
into the Angel in the House or copies of the Virgin Mary, because acknowledging that they are normal, sexual women would have undermined their credibility. While it is certainly laudable that women reporting sexual assault are-for once-not depicted as "loose women," these photographic representations remain highly problematic because they still reiterate stereotypical, patriarchal notions of femininity. Thus, this representation is, in fact, adverse to the idea of a new climate for two reasons: First, turning women into angelic virgins to establish their credibility is a strategy based on the belief that if women are in any way sexual, they are complicit in the sexual crimes they have been the victims of. Hence, this patriarchal strategy of denouncing survivors does not only remain unchallenged-it is also implicitly reaffirmed. Secondly, removing these women from actual living persons to a celestial sphere makes it hard for female readers to connect to them. Consequently, this feature cannot inspire the same bonding effect with the readers as the direct communication of survivors on social media platforms does.

15 The cover photo of the story follows a different pictorial approach. On the black and white photo, all women are clad in dark clothes and placed on identical chairs in identical poses. The background is all white. Underneath each chair, the year in which they were raped is given. The reduced black and white approach and the simple chair might be an attempt to simulate the factual objectivity of an interrogation room. The self-sameness produced through the women's poses links the image to its subtitle "an unwelcome sisterhood." The term "sisterhood" can be understood as index to second wave feminism's idea of universal sisterhood, the notion that all women are united in the feminist battle because of their shared experience as women. This notion of a sisterhood, though an unwelcome one, since the shared experience here is rape, is expounded on in the essay section of the story. Malone and Demme write:

The women have found solace in their number-discovering that they hadn't been alone, that there were others out there who believed them implicitly, with whom they didn't need to be afraid of sharing the darkest details of their lives. They are scattered all over the country-ten different states are represented-and most of them had no contact with their fellow accusers until recently. But since reading about each other's stories in the news, or finding one another on social media, or meeting in person at the photo shoots arranged by New York, many of the women have forged a bond. It is, as Tarshis calls it, 'a sorrowful sisterhood.' (n. pag.)

16 However, in my reading, this sisterhood, a sense of a female community, is not conveyed by the pictures that accompany the text. The portraits focus on the women individually. The cover image depicts them all within the same frame, but in isolation from each other. They are not interacting in any way-they are neither touching each other nor looking at each other nor talking to each other. In fact, because their images are arranged along an imaginary grid, it is transparent that they were never actually sitting next to each other in the same room but were rather edited into a single photograph after the shoot. The imagery of "Cosby: The Women" thus does not communicate female bonding but rather suggests looking at the women as an assemblage of pieces of evidence or a de-individualized collective defined by the patriarch "Cosby." What is more, the black-and-white color scheme of the cover may also translate on into a black-and-white view of the case-a view which does not translate well into fair and balanced trials. Maybe most significantly, the transmedial strategy of NYmag's coverage of the Cosby testimonies, the Instagram audiograms, were relatively ineffective. They did not 
manage to spark an online discussion enabling the audience to contribute. More significant was what happened on social media after the publication of the story: Journalist Elon James White started a Twitter hashtag referring to the cover image, called "\#theemptychair," which started a discussion about the many women who did not dare testify. Within the next four weeks, the hashtag was retweeted over 12,000 times with people commenting and sharing their stories.

In conclusion, NYmag's cover story about the "Cosby testimonies" is beyond any doubt an important piece of journalism, but it also showcases the many pitfalls in the struggle to find a language, particularly a visual one, to depict victims of sexual abuse positively within the framework of print media. Additionally, it gives insight into the difficulty of community-building within that medium's framework.

Time Magazine's cover photo of 2017's "silence breakers" does not reiterate the stereotypical representation of women as "angelic" that can be found in the NY mag story, yet it is marred by similar problems overall. The cover photo is in line with the look of the Time's Up movement at the time of the Golden Globes in early January 2018. All women were clad in black to signal "silent protest" at this red-carpet event. Similarly, in the photo, all women are wearing black. They are gazing directly at the viewer with a challenging look on their faces. One of them remains anonymous with only her arm being inside the frame. The overall color composition is a muted blueishgray. By importing the look of Time's Up, the image also imports the controversy around this initiative. The call for black clothes as a sign of silent protest and mourning was criticized as a misguided choice. Some felt that if the intention was to signal that the time of quiet endurance was up and the time for women to speak up had come, then neither a silent protest nor the color of silent mourning were the right choices (e.g., Wang). Others claimed that this was a hypocritical initiative (e.g., Rose McGowan et al., in a now deleted Twitter thread (see Park)) for the same women who had worked with Harvey Weinstein for years were taking a merely symbolical stand. The critique of the connotations of the selected color palette also applies to the cover-the black clothes, the muted color scheme, the women who talk neither to each other, nor to the onlooker, but merely give a silent glare, ironically clash with the title on the cover: "The Silence Breakers." Inside the magazine, the impression of silent mourning evoked by color selection, poses and somber facial expressions at times becomes so dominant that it seems the women depicted are dead, historic figures of a past era, rather than as living activists. While sharing sadness and mourning certainly is an important part of the movement, reducing the women to that takes the edge off it. What is more, these images do not seem geared towards encouraging readers to connect and interact with the women. Instead of giving more momentum to the movement, they rather create distance and a sense of closure concerning the movement.

\section{Conclusion}

The stigmatization of women as gossips has been used as a strategic tool to keep women from solidarizing with one another openly. Especially women who spoke up against mistreatment, abuse, harassment or rape by men were thus discredited and/or silenced. Recently, a paradigm shift has occurred in the way the media represent such women-now, they are listened to and depicted as credible. However, this does not mean that print media representation of these women is free from stereotypes. Also, 
talking about "media" in an unspecific plural with regard to the current representations of women who break the silence about abuse, harassment and discrimination, as Dubravka does, is certainly problematic. The framing, the conventions and the infrastructure of print and social media have to be clearly differentiated in order to recognize the chances and problems of the discourse about contemporary feminist online activism and rape survivors.

On the one hand, hashtag feminism on social media platforms has been criticized as being nothing more than an outgrowth of celebrity culture, thus privileging certain voices over others and allowing for very convenient ways of feeling part of activism without actually working on social and legal change. On the other hand, the audience activation of social media is more closely related to going out on the street and protesting than the kind of reception enabled by traditional media, and it is often the place were initiatives for such protests take their root. Print media outlets, in contrast, naturally struggle to furnish this kind of immediate communication and connection, though they have started to imitate and adapt some of the strategies of social media platforms. Still, their representation sometimes creates distance between women, rather than to connecting them.

This essay has offered an analysis and interpretation of two print features, namely NYmag and Time Magazine, which followed different strategies to represent women fighting against sexual harassment and rape. NYmag lifts the women who accused Cosby of rape into a celestial sphere by depicting them as angelic. Thus, they seem far removed from the perspective of the female readership. Time Magazine visually represents feminist activists in and around the \#MeToo movement as historic figures of a past era -again, this displaces them from the immediate reality of the readership. What is missing from these photo stretches are images of women actually interacting with each other, images that succeed in conveying the notion of a shared cause, of a vivid, social movement and which invite the inclined reader to not just look at them, but to want to become part of the picture/community. The absence of images of women who are actively communicating with each other testifies to the persisting stigma of women as gossips. The images in the sample suggest that there is a strong impulse to separate groups of women into individuals and silence them on the visual level-lest they appear again as gossiping women hatching a plot against men. These stereotypes, reinforced for so long in the media, have become the phantoms that haunt contemporary attempts to represent women's activism positively.

\section{BIBLIOGRAPHY}

@elonjames (Elon James White) et al. “TheEmptyChair.” Twitter, 27 July, 2015. https:// twitter.com/hashtag/TheEmptyChair?src=hash. Web. [account has been deactivated]

Banet-Weiser, Sarah. Empowered: Popular Feminism and Popular Misogyny. Duke UP, 2018. 
Banet-Weiser, Sarah et al. "Postfeminism, Popular Feminism and Neoliberal Feminism? Sarah Banet-Weiser, Rosalind Gill and Catherine Rottenberg in Conversation." Feminist Theory, vol. 21, no. 1, 2019, pp. 3-224.

Blakley, Johanna. "Social Media and the End of Gender." TEDWomen 2010. https://www.ted.com/ talks/johanna_blakley_social_media_and_the_end_of_gender/discussion\#t-317290.22 April 2018.

Fowler, Susan. "Reflection on One Very, Very Strange Year at Uber." Susan Fowler. 19

February 2017. Accessed 21 April 2018. https://www.susanjfowler.com/blog/2017/2/19/ reflecting-on-one-very-strange-year-at-uber

Gray, Herman. “Subject(ed) to Recognition.” American Quarterly, vol. 65, no. 4, 2013, pp. 771-798.

Griffin, Susan. “Rape: The All-American Crime.” Ramparts, vol. 10, no. 3, 1971, pp. 26-35.

Hearn, Alison. "Verified: Self-presentation, Identity Management, and Selfhood in the Age of Big Data." Journal of Popular Culture, vol. 15, no. 2, 2017, pp. 62-77.

Leaper, Campbell and Heithre Holiday "Gossip in Same-Gender and Cross-Gender Friends' Conversations.” Personal Relationships, vol. 2, 1995, pp. 237-246.

Malone, Noreen and Amanda Demme. “'I'm No Longer Afraid': 35 Women Tell Their Stories About Being Assaulted by Bill Cosby, and the Culture That Wouldn't Listen." NYmag online, The Cut. Accessed 26 July 2015. https://www.thecut.com/2015/07/bill-cosbys-accusers-speak-out.html.

McRobbie, Angela. "Post-feminism and Popular Culture." Feminist Media Studies, vol. 4, no. 3, 2004, pp. 255-264.

Mendes, Kaitlynn et al. "\#MeToo and the Promise and Pitfalls of Challenging Rape Culture through Digital Feminist Activism." European Journal of Women's Studies, vol. 25, no. 2, 2018, pp236-246.

No author. "2016 Feature, Large Newsroom, Winner. Cosby: The Women. The accounts of 35 Women who have Accused Bill Cosby of Sexual Assault." Online Journalism Awards. No date. Accessed 22 April 2018. https://awards.journalists.org/entries/cosby-the-women/

Park, Andrea. "Rose McGowan Calls Out Golden Globes Black Dress Protest, 'Hollywood Fakery`." CBS News. 8 January 2018. Accessed 22 June 2020. https://www.cbsnews.com/news/rosemcgowan-calls-out-golden-globes-black-dress-protest-hollywood-fakery/

Pew Research Center. "Social Media Use by Gender." Pew Research Center - Internet and Technology. 21 January 2017. Accessed 21 April 2018. https://www.pewresearch.org/internet/chart/socialmedia-use-by-gender/.

Rysman, Alexander. "How the "Gossip" Became a Woman." Journal of Communication, Winter 1977, pp. 176-180.

Wang, Connie. “The No-Win Conundrum Of The Golden Globes' \#MeToo Red Carpet."

Refinery 29, 5 January 2018. Accessed 6 February 2018. https://www.refinery29.com/en-us/ 2018/01/186945/golden-globes-red-carpet-protest-sexual-assault

Zarkov, Dubravka and Kathy Davis. "Ambiguities and Dilemmas around \#MeToo: \#ForHowLong and \#Where To?" (Editorial). European Journal of Women's Studies 25.1 (2018), pp. 3-9. 


\section{ABSTRACTS}

There is a long-standing connection between gender and gossip in Western culture as the communication amongst women has been stigmatized as gossip. Long before \#MeToo, women who had become victims of sexual abuse and who spoke out against sexual violence were pillorized through gossip and stigmatized as gossips in the public sphere. As a consequence, women have resorted to private forms of communication-so-called "whisper networks"-to warn each other about abuse and harassment. However, the \#MeToo-movement has shifted this network from the private sector into that strange hybrid of private and public communication that is social media. The "mainstreaming" of feminist activism achieved through hashtag feminism has had repercussions for the representation of rape survivors and feminist activists in traditional, analog media. The particulars of these repercussions are what this essay seeks to analyze. The traditional public forum of the printed press started to represent these women as trustworthy witnesses-in a dramatic deviation from previous patterns of representation. While the connection between femininity and gossip thus seems to have been severed, this does not, however, mean that the representation of women in the media has been fundamentally altered. Through a semiotic analysis of the visual representations of women in print media around and after \#MeToo, this essay will critically call into question the extent of the perceived paradigm shift in the context of \#MeToo and the trial of Bill Cosby in 2017.

\section{INDEX}

Keywords: gossip, gender, \#MeToo, whisper network, print media, new media, social media, Cosby trial, hashtag feminism, postfeminism

\section{AUTHOR}

\section{MARIA VERENA PETERS}

Maria Verena Peters studied English and Comparative literature at Ruhr-University Bochum, Germany. She worked as a lecturer in American Studies, Cultural Studies and English literature at Ruhr-University Bochum, the University of Siegen and the University of Wuppertal. In 2015, she completed her Ph.D. thesis on "Age in Crisis at the Turn of the 21st Century" at Siegen University. She is currently employed at FernUniversität Hagen and working on a publication on the representation of female breasts in mass media together with Sophie G. Einwächter. Her research interests include popular culture and gender, the intersectionality of gender and age, television culture, fan studies and gothic fiction. 